\title{
The Empirical Relationship between Stock Returns, Return Volatility and Trading Volume in the Brazilian Stock Market
}

\author{
Otávio Ribeiro de Medeiros ${ }^{\dagger}$ \\ University of Brasília \\ Bernardus Ferdinandus Nazar Van Doornik * \\ Brazil Central Bank
}

\begin{abstract}
We investigate the empirical relationship between stock returns, return volatility and trading volume in the Brazilian stock market (Bovespa). Our sample contains stock return and trading volume data from a theoretical portfolio including stocks participating in the Bovespa Index (Ibovespa) extending from 01/03/2000 through 12/29/2005. The empirical methods used include cross-correlation analysis, unit-root tests, bivariate simultaneous equations regression analysis, GARCH and VAR models, and Granger causality tests. We find support for a contemporaneous as well as a dynamic relationship between stock returns and trading volume, implying that forecasts of one of these variables can be only slightly improved by knowledge of the other. Besides, our results indicate that contemporaneous and dynamic relationships between return volatility and trading volume also exist. Additionally, by applying Granger's causality test, we find that return volatility contains information about upcoming trading volume and vice versa.
\end{abstract}

Key words: return volatility; trading volume; GARCH; VAR; Granger causality.

Received in 10/10/2007; revised in 01/03/2008; accept in 03/24/2008.

Corresponding authors:

+ Full Professor in University of Brasília

Campus Darcy Ribeiro, ICC ala Norte, subsolo,

módulo 25, Brasília , DF, Brazil, CEP 70910-970

e-mail:otavio@unb.br

Phone: +55 61 3273-8538 t Analist Brazil Central Bank

SQN, 407, Bloco Q, apto. 303, Brasília, DF,

Brazil CEP 70855-170

e-mail: bernardus.doornik@bcb.gov.br

Phone: +55 61 8429-2988

Editor's note: This paper was accepted by Alexsandro Broedel Lopes. 


\section{INTRODUCTION}

$\mathrm{E}$ mpirical studies on stock markets usually focus on stock prices and their behavior over time. However, due to some undesirable stochastic properties of stock prices, especially non-stationarity, most researchers concentrate on stock returns rather than prices. Based on the existing information about a firm, its stock returns reflects the investors' expectations on the future performance of that firm. The arrival of new information makes investors to adapt their expectations and this is the main cause for price and return changes. However, since investors are heterogeneous when interpreting new information, stock returns may stay unchanged even though new information is brought to the market. This will be the case if some investors interpret some bits of information as good news while others find it to be bad news. Therefore, price changes indicate the average reaction of investors to news. On the other hand, stock returns may only change if there is positive trading volume. As it happens with returns, trading volume and its changes mainly reflect the available set of relevant information perceived by the market. Differently from stock prices and returns, however, a relevant change in investors' expectations always leads to an increase in trading volume which therefore reflects the sum of investors' reactions to news. Studying the joint dynamics of stock returns and trading volume therefore improves the understanding of the microstructure of stock markets.

Our study is inspired on a previous work which investigates the relation between stock returns, return volatility and trading volume in the Austrian stock market (MESTEL; GURGUL; MAJDOSZ, 2003). Our investigation cover not only contemporaneous but also dynamic relationships. Our results indicate that there is an association between stock returns and trading volume in the Brazilian stock market. This implies, inter alia, that knowledge of trading volume may improve short-run return forecasts. Moreover, we find support for the hypothesis of a positive relationship between return volatility and trading volume. Actually, this positive relationship shows evidence of a mutual Granger causality between return volatility and trading volume.

The paper is organized as follows: In section 2 we present a brief discussion on the extant literature and in Section 3 we describe the methods used in our empirical investigation. In section 4 we show our findings with respect to the contemporaneous and the dynamic relationship between stock returns, return volatility and trading volume. Section 5 concludes the paper.

\section{LITERATURE REVIEW}

Several studies have examined the empirical relationship between trading volume and stock returns. Some of these have investigated the connection between trading volume and price changes by itself, usually using price indexes (KARPOFF, 1987; HIEMSTRA and JONES, 1994; BRAILSFORD, 1996; LEE and RUI, 2002). The results of these studies diverge from each other, although a positive relationship is mainly reported. Also, the association between stock return volatility and trading volume has been analyzed by several authors since the 1980's (KARPOFF, 1987; BROCK; LEBARON, 1996; LEE; RUI, 2002; MESTEL; GURGUL; MAJDOSZ, 2003).

Recently, stochastic time series models of conditional heteroscedasticity have been used to explore this relationship (LAMOUREUX; LASTRAPES, 1990; ANDERSEN, 1996; BRAILSFORD, 1996; GALLO; PACINI, 2000; OMRAN; MCKENZIE, 2000). Most of these studies mostly conclude that there is evidence of a strong relationship, which is both 
contemporaneous as well as dynamic, between return volatility and trading volume. However, there is reported evidence using intraday data from the Dow Jones Industrial Average stocks of only significant lead/lag relations but not of contemporaneous correlation between return volatility and trading volume (DARRAT; RAHMAN; ZHONG, 2003).

A recent study scrutinizes the empirical relationship between stock returns, return volatility and trading volume on the Austrian stock market (MESTEL; GURGUL; MAJDOSZ, 2003). The authors find only weak support for a contemporaneous and dynamic relationship between stock returns and trading volume, implying that forecasts of one of these variables cannot be improved by knowledge of the other. However, they find evidence of a strong contemporaneous relationship between return volatility and trading volume and that return volatility contains information about upcoming trading volume.

\section{METHODOLOGY}

\subsection{Sample and Data}

Our data set comprises daily market price and trading volume series for a theoretical portfolio consisting of assets belonging to all (57) firms participating in Ibovespa, the Brazilian stock-exchange (Bovespa) index. Overall, these assets account for over $80 \%$ of Bovespa's market capitalization. The investigation covers the period extending from $01 / 03 / 2000$ to $12 / 29 / 2005$. Ibovespa is a market-capitalization weighted stock index that indicates the total return performance of all securities traded in the prime market segment of Bovespa and works as a benchmark for institutional investors.

All trading volume and stock index data are primarily provided by Bovespa and were collected from Economatica ${ }^{\circledR}$ s database. Continuously compounded stock returns are calculated from daily stock prices at close, adjusted for dividend payouts and stock splits. Since Brazilian inflation is not negligible, around $11.5 \%$ per year during the 2001-2005 period, according to the Brazilian general price index, IGP-DI, we deflate the trading volume and the Ibovespa series using the IGP-DI itself. The data on the IGP-DI were collected from IPEA - Instituto de Pesquisa Econômica Aplicada's website (IPEA, 2005). Since trading volumes in Brazilian currency (BRL\$) are quite large numbers, we transformed the series into an index, with the first observation being set to 100 .

\subsection{Cross-Correlation Analysis}

As a first step to investigate the relationship between stock return and trading volume, we calculate the cross-correlation coefficients $\rho\left(R_{t}, V_{t}\right)$ for all firms:

$$
\rho\left(R_{t}, V_{t}\right)=\frac{\operatorname{Cov}\left(R_{t}, V_{t}\right)}{\sigma\left(R_{t}\right) \cdot \sigma\left(V_{t}\right)}
$$

where $R_{t}$ and $V_{t}$ stand for stock return and trading volume, respectively, on day $t, \operatorname{Cov}(; ;)$ denotes covariance and $\sigma(\cdot)$ is standard deviation.

\subsection{Testing for Unit Roots}

To test for the contemporaneous as well as causal relation between trading volume, stock returns and return volatility, we use an unrestricted Vector Autoregressive (VAR) model that can be sensitive to non-stationarity. Therefore we check the hypothesis of whether the 
time series of stock returns and trading volume are stationary by using the augmented DickeyFuller (ADF) test. This test is based on the regression:

$$
\Delta y_{t}=\mu+\gamma y_{t-1}+\sum_{i=1}^{p} \delta_{i} \Delta y_{t-i}+\varepsilon_{t}
$$

where $y$ is the variable being tested for unit roots (stock return or trading volume), $\mu, \gamma$ and $\delta$ are model parameters and $\varepsilon_{t}$ is an I.I.D Gaussian $\left(0, \sigma^{2}\right)$ white noise error term.

The unit root test is carried out by testing the null hypothesis $\gamma=0$ against the one sided alternative $\gamma<0$. The t-Student-statistic of the estimated parameter $\gamma$ does not have a conventional t-distribution under the null hypothesis of a unit root. Instead, we use the critical values recommended by MacKinnon (1991). If the ADF t-statistic for $\gamma$ lies to the left of these values, the null hypothesis can be rejected.

\subsection{Stock Returns and Trading Volume}

The empirical procedure in this section further tests the contemporaneous relationship between stock returns and trading volume. We apply the multivariate model proposed in a previous work, which is defined by the two equations below (LEE; RUI, 2002):

$$
\begin{aligned}
& R_{t}=\alpha_{0}+\alpha_{1} V_{t}+\alpha_{2} V_{t-1}+\alpha_{3} R_{t-1}+u_{t} \\
& V_{t}=\beta_{0}+\beta_{1} R_{t}+\beta_{2} V_{t-1}+\beta_{3} V_{t-2}+v_{t}
\end{aligned}
$$

where $\alpha_{i}$ and $\beta_{i}, i=1,2,3$, are model coefficients and $u_{t}$ and $v_{t}$, denote I.I.D Gaussian $\left(0, \sigma^{2}\right)$ white noise error terms. To estimate the model coefficients we apply the full-information maximum likelihood method.

Although we may find stock return levels and trading volume to be mostly uncorrelated that does not mean that there is no relationship between these variables at all. It is often reported that price fluctuations tend to increase if there is a high trading volume, especially in times of bullish markets. That is, there might be a relation between higher order moments of stock returns and trading volume. We scrutinize this by extending a model which relates trading volume to squared stock returns by means of the following regression (BRAILSFORD, 1996):

$$
V_{t}=\alpha_{0}+\phi_{1} V_{t-1}+\phi_{2} V_{t-2}+\alpha_{1} R_{t}^{2}+\alpha_{2} D_{t} R_{t}^{2}+e_{t}
$$

where $D_{t}$ denotes a dummy variable that equals 1 if the corresponding return $R_{t}$ is negative and 0 otherwise. To avoid the problem of serially correlated residuals documented in Brailsford (1996) we include lagged values of $V_{t}$ up to lag 2. The estimate of parameter $\alpha_{1}$ measures the relationship between return volatility and trading volume irrespective of the direction of the price change. The estimate of $\alpha_{2}$, however, measures the degree of asymmetry in that relationship.

\subsection{Conditional Volatility and Trading Volume}

Eventually, the finding of a contemporaneous relationship between trading volume and squared stock returns raises the question of whether trading activity can be identified as a potential source for the observed serial dependence (persistence or hysteresis) in return volatility. This is motivated by the theoretical works on the Mixture of Distribution Hypothesis (MDH) (CLARK, 1973; EPPS; EPPS, 1976; TAUCHEN; PITTS, 1983; LAMOUREUX; LASTRAPES, 1990; ANDERSEN, 1996). This hypothesis affirms that stock returns are generated by a mixture of distributions in which the number of information arrivals into the market represents the stochastic mixing variable. Return data can be regarded as a 
stochastic process, conditional on the information flow, with a changing second order moment reflecting the intensity of information arrivals. Under the assumptions of the MDH model, innovations to the information process lead to momentum in stock return volatility.

Since the information flow into the market is widely unobservable, we use trading volume as a proxy. Systematic variations in trading volume are assumed to be caused only by the arrival of new information. Trading volume typically exhibit the assumed time dependence. We specify the stochastic process of stock returns as a simple GARCH $(1,1)$ process with an autoregressive term in the mean equation and trading volume as an additional predetermined regressor in the conditional variance equation:

$$
\begin{gathered}
R_{t}=\mu+\phi R_{t-1}+\varepsilon_{t} \\
\varepsilon_{t} \mid I_{t-1} \sim \underset{2}{\operatorname{Gaussian}\left(0, \sigma_{t}\right)} \\
\sigma_{t}=\alpha_{0}+\alpha_{1} \varepsilon_{t-1}+\beta_{1} \sigma_{t}+\gamma_{1} V_{t}+\zeta_{t}
\end{gathered}
$$

where $I_{t-1}$ denotes the set of information available at $t-1$ and $\sigma^{2}$ stands for the variance of $\varepsilon_{t}$. The parameters of equations (7) and (8) are estimated by means of maximum likelihood. Note that in equation (8) the sum of parameters $\alpha_{1}$ and $\beta_{1}$ is a measure of the persistence in the variance of the unexpected return $\varepsilon_{t}$ taking values between 0 and 1 . The more this sum tends to unity the greater the persistence of shocks to volatility, which is also known as volatility clustering or hysteresis.

\subsection{Causal Relationship}

Up to now we have mainly concentrated on the contemporaneous relationship between stock returns, return volatility and trading volume. In this section we extend our analysis by examining the dynamic (causal) relationship. Testing for causality is important since it can help to better understand the microstructure of stock markets and can also have implications for other markets (e.g. options markets).

We investigate causality between trading volume and stock returns and between trading volume and return volatility in both directions by means of Granger's causality test (GRANGER, 1969). A variable $y$ is said to not Granger-cause a variable $x$ if the distribution of $x$, conditional on past values of $x$ alone, equals the distribution of $x$, conditional on the past of both $x$ and $y$. On the other hand, if this equality does not hold, y is said to Granger-cause $x$. However, this does not mean that $y$ causes $x$ in the more common sense of the term but only indicates that $y$ precedes $x$.

To test for Granger causality we use a bivariate VAR model of order p of the form:

$$
\begin{aligned}
& R_{t}=\mu_{R}+\sum_{i=1}^{p} \alpha_{i} R_{t-i}+\sum_{i=1}^{p} \beta_{i} V_{t-i}+u_{t} \\
& V_{t}=\mu_{V}+\sum_{i=1}^{p} \alpha_{i} V_{t-i}+\sum_{i=1}^{p} \beta_{i} R_{t-i}+v_{t}
\end{aligned}
$$

The null hypotheses that $R$ does not Granger-cause $V$ and that $V$ does not Granger cause $R$ imply that $\beta_{i}(i=1, \ldots, p)$ are all equal to 0 . To test the null we calculate the Fstatistic:

$$
F=\frac{S S E_{r}-S S E_{u}}{S S E_{u}} \frac{N-2 p-1}{p}
$$

where $S S E_{r}$ stands for the sum of squared residuals of the restricted regression (i.e. $\beta_{1}=\ldots=$ $\left.\beta_{\mathrm{p}}=0\right), S S E_{u}$ is the sum of squared residuals of the unrestricted equation, and $N$ is the number 
of observations. The statistic in equation (11) is asymptotically $\mathrm{F}$ distributed under the null with $p$ degrees of freedom in the numerator and $(N-2 p-1)$ in the denominator. The parameters $\alpha_{\mathrm{i}}$ and $\beta_{\mathrm{i}}$ in equation (9) and (10) are estimated by OLS. To decide upon the appropriate order $p$ of the VAR we use the adjusted $\mathrm{R}^{2}$ and the Akaike and the Schwartz information criteria (AIC/SIC). These are measures of goodness of fit that adjust for the loss of degrees of freedom resulting from adding additional lags to the model. The bivariate regressions in (9) and (10) are re-estimated with squared values of stock returns instead of return levels.

\section{RESULTS}

\subsection{Descriptive Statistics}

We started our investigation with some basic descriptive analysis of the time series of stock returns and trading volume, which are shown on Figure 1 and Table 1.

The mean daily stock return is equal to $0.000398 \%$, with a standard deviation of $2.6 \%$. The 'fat-tailed and highly-peaked' stylized fact that is often reported for return series is mostly present in our data. The excess kurtosis is 0.501 and the return skewness is 0.155 . Applying the Jarque-Bera test for normality we find strong support for the hypothesis that the time series of stock returns do not correspond to a normal distribution. 
Figure 1: Ibovespa' trading volume and stock returns

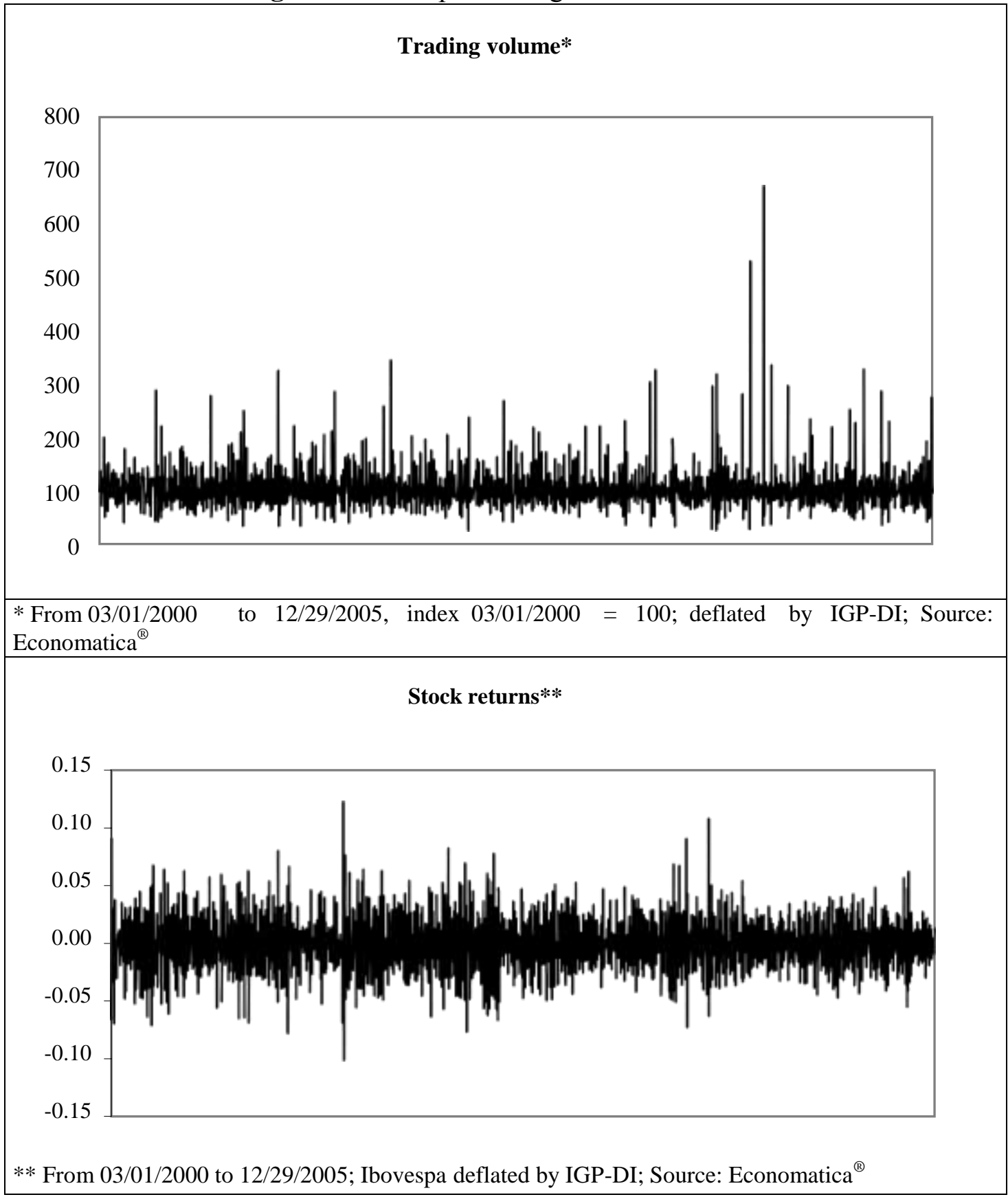

Unlike stock returns, return volatility as well as trading volume present strong persistence in their times series, which is investigated in this section by means of a GARCH model. Hence, in accordance with the stylized facts of volume series documented in the extant literature, our volume data show remarkably non-Gaussian characteristics, i.e. positive excess kurtosis and skeweness to the right (Andersen, 1996). In addition, we find that log-values of trading volume can be assumed to follow a normal distribution.

To proxy return volatility we use squared values of daily stock returns. These time series display the usual time dependency of stock returns in the second order moment (volatility persistence or hysteresis) implying that returns cannot be assumed to be I.I.D. 
Table 1: Statistics summary

\begin{tabular}{l|c|c|c|c}
\hline \multicolumn{5}{c}{ Sample: 11492} \\
\hline Mean & $\mathrm{V}^{*}$ & $\mathrm{R}$ & $\mathrm{R}^{2}$ & $\log (\mathrm{V})$ \\
Median & 951.4742 & $3.98 \mathrm{E}-06$ & 0.000683 & 6.767235 \\
Maximum & 873.8831 & -0.000313 & 0.000329 & 6.772947 \\
Minimum & 3991.374 & 0.122416 & 0.014986 & 8.291891 \\
Std. Dev. & 171.7479 & -0.101463 & 0.000000 & 5.146028 \\
Skewness & 425.3271 & 0.026148 & 0.001081 & 0.427677 \\
Kurtosis & 1.590360 & 0.155579 & 4.671124 & -0.072310 \\
Jarque-Bera & 8.436255 & 3.501411 & 40.68527 & 3.223403 \\
Probability & 2464.489 & 21.63393 & 93650.80 & 4.399939 \\
\hline
\end{tabular}

* BRL\$ $10^{6}$

\subsection{Cross-Correlation Analysis}

Table 2 presents cross-correlation coefficients between stock returns, return volatility, and trading volume.

Table 2: Cross-correlation coefficients between stock returns, return volatility and trading volume

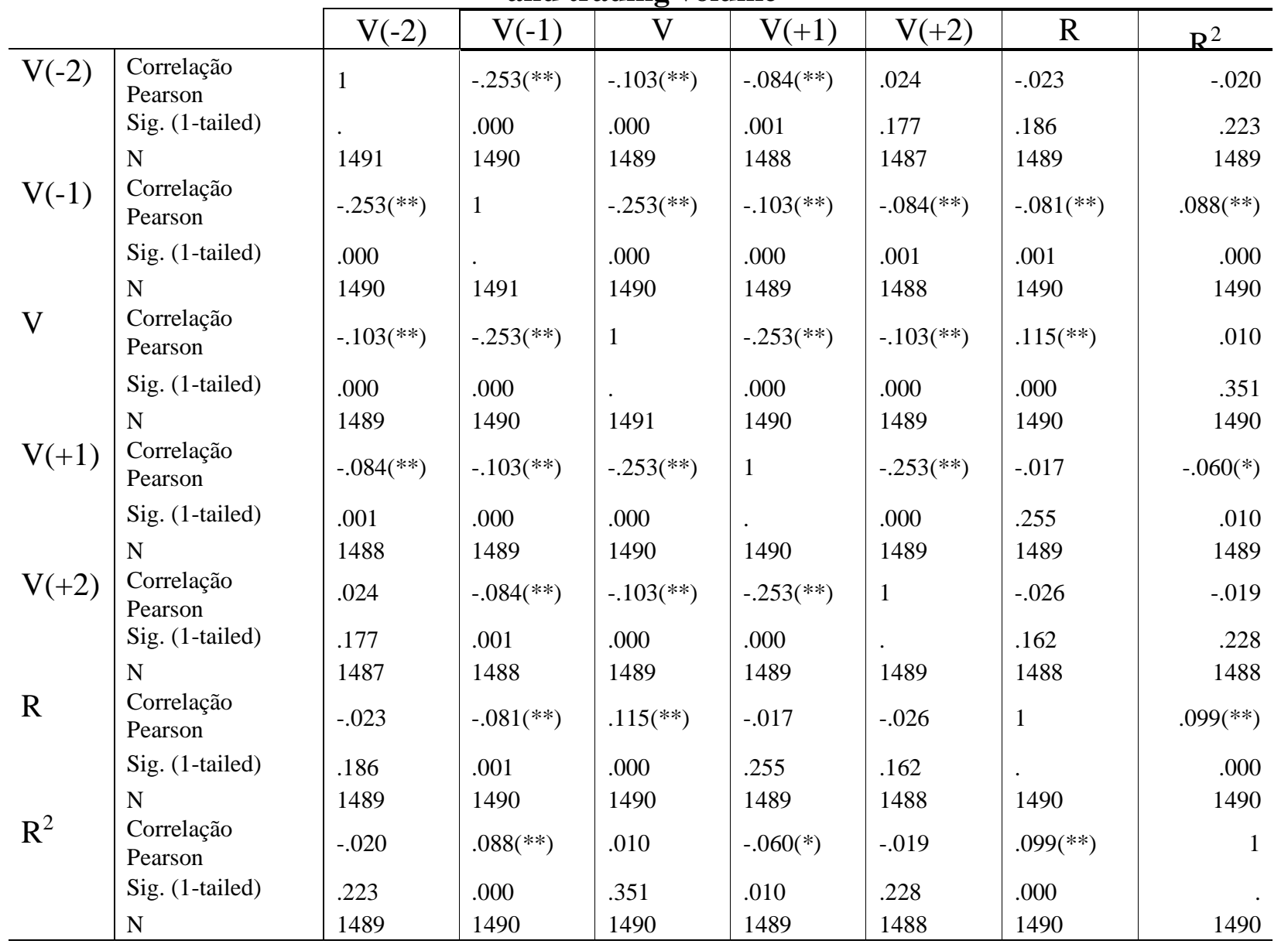

** Correlation is significant at the 0.01 level (1-tailed).

* Correlation is significant at the 0.05 level (1-tailed). 
From Table 1 we find that there is a low but significant contemporaneous positive correlation between stock return levels and trading volume. The correlation is even weaker but significant if one computes the correlations between stock returns and lagged and lead trading volume.

On the other hand, Table 1 indicates that there is no positive contemporaneous relationship between trading volume and return volatility. There is, however, a low positive but significant correlation between lagged trading volume and return volatility and a low negative correlation between lagged return volatility and trading volume. This is a first indication that there might exist a causal relationship between trading volume and return volatility. These findings are further investigated in the next sections. The results presented in this section are in accordance with previous empirical findings (BROCK; LEBARON, 1996; MESTEL; GURGUL; MAJDOSZ, 2003).

\subsection{Unit Root Tests}

As discussed in Section 3.3, after conducting ADF tests according to equation (2) for the time series of stock returns and trading volume we find the parameter $\gamma$ to be negative and statistically significant at the sensible levels. Hence we come to the conclusion that all three time series, i.e. stock return, stock return volatility and volume $\left(R, R^{2}\right.$ and $\left.V\right)$ can be considered stationary. Table 3 shows the results of the unit-roottests.

Table 3: Results of the unit root tests

\begin{tabular}{c|c|c}
\hline Variable & ADF statistics & Critical value $(1 \%)^{*}$ \\
\hline$R$ & -29.71375 & -3.4377 \\
$R^{2}$ & -14.04838 & -3.4377 \\
$V$ & -21.33754 & -3.4377 \\
\hline
\end{tabular}

*MacKinnon critical values for rejection of hypothesis of a unit root.

\subsection{Contemporaneous Relationship between Stock Returns and Trading Volume}

The tests for contemporaneous relationships between stock returns and trading volume were described in Section 3.4, and they are performed by means of equations (3) and (4), which are jointly estimated by full-information maximum likelihood. The results of these are shown on Table 4.

Our findings confirm the cross-correlation analysis that there is evidence of a contemporaneous relationship between stock returns and trading volume. The parameters $\alpha_{1}$ in equation (3) is significant at the $1 \%$ level and it is positive. There is also evidence of a lagged relationship between stock returns and trading volume, since the parameter $\alpha_{2}$ in equation (3) is also positive, although significant only at the $6.7 \%$ level. However, the contemporaneous relationship between stock returns and trading volume is not simultaneous, since the parameter $\beta_{1}$ in equation (4) is not significant, which means that $R$ depends on $V$, but $V$ does not depend on $R$. The strong time dependency of trading volume is documented by highly significant parameters $\beta_{2}$ and $\beta_{3}$ in equation (4).

It has been often reported that price fluctuations tend to increase if there is high trading volume, especially in times of bullish markets. That is, there might be a relation between higher order moments of stock returns and trading volume. We investigated this by extending a model which relates trading volume to squared stock returns by the following regression (BRAILSFORD, 1996):

$$
V_{t}=\alpha_{0}+\phi_{1} V_{t-1}+\phi_{2} V_{t-2}+\alpha_{1} R_{t}^{2}+\alpha_{2} D_{t} R_{t}^{2}+e_{t}
$$


where $D_{t}$ denotes a dummy variable that equals 1 if the corresponding return $R_{t}$ is negative and 0 otherwise. To avoid the problem of serially correlated residuals previously documented, we include lagged values of $V$ up to lag 2.

After this, we find $e_{t}$ in equation (5) to be largely non-serially correlated. The estimate of parameter $\alpha_{1}$ measures the relationship between return volatility and trading volume irrespective of the direction of the price change. The estimate of $\alpha_{2}$, however, measures the degree of asymmetry in that relationship.

Table 4: Joint estimation of equations (3) and (4) Estimation Method: Full Information Maximum Likelihood (Marquardt)

\begin{tabular}{l|c|c|c|c}
\hline \multicolumn{5}{c}{ Sample: 1 1492 } \\
\hline \multicolumn{5}{c}{ Convergence achieved after 4 iterations } \\
\cline { 2 - 5 } & Coefficient & Std. Error & t-Statistic & Prob. \\
\hline$\alpha_{0}$ & -0.031786 & 0.011394 & -2.789817 & 0.0053 \\
$\alpha_{1}$ & 0.000252 & $8.45 \mathrm{E}-05$ & 2.983487 & 0.0029 \\
$\alpha_{2}$ & $4.74 \mathrm{E}-05$ & $2.59 \mathrm{E}-05$ & 1.833342 & 0.0669 \\
$\alpha_{3}$ & -0.452521 & 0.024478 & -18.48669 & 0.0000 \\
$\beta_{0}$ & 155.5020 & 3.315029 & 46.90819 & 0.0000 \\
$\beta_{1}$ & 144.2750 & 104.3029 & 1.383232 & 0.1667 \\
$\beta_{2}$ & -0.292207 & 0.015956 & -18.31379 & 0.0000 \\
$\beta_{3}$ & -0.172034 & 0.025680 & -6.699136 & 0.0000 \\
\hline
\end{tabular}

Log Likelihood $-4111.776$

Determinant residual covariance 0.793950

Equation (3): $\mathrm{R}=\alpha_{0}+\alpha_{1} * \mathrm{~V}+\alpha_{2} * \mathrm{~V}(-1)+\alpha_{3} * \mathrm{R}(-1)$

Observations: 1490

\begin{tabular}{lllr} 
R-squared & 0.145265 & Mean dependent var & $4.82 \mathrm{E}-05$ \\
Adjusted R-squared & 0.143539 & S.D. dependent var & 0.026101 \\
S.E. of regression & 0.024155 & Sum squared resid & 0.867061 \\
Durbin-Watson stat & 2.279031 & & \\
Equation (4): $\mathrm{V}=\beta_{0}+\beta_{1} * \mathrm{R}+\beta_{2} * \mathrm{~V}(-1)+\beta_{3} * \mathrm{~V}(-2)$ & \\
Observations: 1490 & & \\
\hline
\end{tabular}

Applying maximum likelihood to estimate equation (5) lead to the results shown on Table 5. 
Table 5: Estimation results for equation (5) Estimation Method: Full Information Maximum Likelihood (Marquardt)

\begin{tabular}{|c|c|c|c|c|}
\hline \multicolumn{5}{|c|}{ Sample: 11492} \\
\hline \multicolumn{5}{|c|}{ Convergence achieved after 1 iterations } \\
\hline & Coefficient & Std. Error & t-Statistic & Prob. \\
\hline$\alpha_{0}$ & 155.3604 & 3.012434 & 51.57306 & 0.0000 \\
\hline$\phi_{1}$ & -0.290592 & 0.015486 & -18.76459 & 0.0000 \\
\hline$\phi 2$ & -0.176159 & 0.022978 & -7.666507 & 0.0000 \\
\hline$\alpha_{1}$ & 3608.493 & 804.8956 & 4.483181 & 0.0000 \\
\hline$\alpha_{2}$ & -6288.694 & 1864.700 & -3.372496 & 0.0008 \\
\hline \multirow{3}{*}{\multicolumn{5}{|c|}{$\begin{array}{lc}\text { Log Likelihood } & -7614.723 \\
\text { Determinant residual covariance } & 1619.855 \\
\text { Equation (5): } V=\alpha_{0}+\phi_{1}{ }^{*} \mathrm{~V}(-1)+\phi_{2} * \mathrm{~V}(-2)+\alpha_{1} * \mathrm{R}^{2}+\alpha_{2} * \mathrm{DUMMY} * \mathrm{R}^{2} \\
\text { Observations: } 1489\end{array}$}} \\
\hline & & & & \\
\hline & & & & \\
\hline R-squared & 0.103389 & \multirow{4}{*}{\multicolumn{2}{|c|}{$\begin{array}{l}\text { Mean dependent var } \\
\text { S.D. dependent var } \\
\text { Sum squared resid }\end{array}$}} & 106.1928 \\
\hline Adjusted R-squared & 0.100972 & & & 42.51888 \\
\hline S.E. of regression & 40.31516 & & & 2411963. \\
\hline Durbin-Watson stat & 2.067719 & & & \\
\hline
\end{tabular}

We find parameter $\alpha_{1}$ to be positive and significant and parameter $\alpha_{2}$ to be negative and significant. These findings strongly support the hypothesis that higher trading volume is associated with an increase in stock return volatility and that this relationship is more pronounced when stock prices increase. Good news (increasing prices) therefore induces more trading volume than bad news (declining prices), which is also consistent with the assumptions put forward by behavioral finance (RITTER, 2003).

4.5. Conditional Volatility and Trading Volume

The results of the joint estimation by maximum likelihood of equations (6) to (8) are depicted on Tables 6 and 7. 
Table 6: Joint restricted estimation of equations (6) to (8)

Dependent Variable: $\mathrm{R}$

Method: ML - ARCH

Date: 04/13/06 Time: 17:32

Sample(adjusted): 31492

Included observations: 1490 after adjusting endpoints

Convergence achieved after 13 iterations

\begin{tabular}{l|c|l|c|c}
\hline & Coefficient & Std. Error & z-Statistic & Prob. \\
\hline $\mathrm{C}$ & 0.000179 & 0.000530 & 0.336769 & 0.7363 \\
$\mathrm{R}(-1)$ & -0.478418 & 0.024741 & -19.33720 & 0.0000 \\
\hline \multicolumn{4}{|c}{ Variance Equation } \\
\hline $\mathrm{C}$ & $3.18 \mathrm{E}-05$ & $9.75 \mathrm{E}-06$ & 3.263173 & 0.0011 \\
$\mathrm{ARCH}(1)$ & 0.104377 & 0.019917 & 5.240555 & 0.0000 \\
GARCH(1) & 0.835882 & 0.032066 & 26.06789 & 0.0000 \\
\hline R-squared & 0.219373 & Mean dependent var & $4.82 \mathrm{E}-05$ \\
Adjusted R-squared & 0.217271 & S.D. dependent var & 0.026101 \\
S.E. of regression & 0.023092 & Akaike info criterion & -4.756244 \\
Sum squared resid & 0.791884 & Schwarz criterion & -4.738437 \\
Log likelihood & 3548.402 & F-statistic & 104.3295 \\
Durbin-Watson stat & 2.279104 & Prob(F-statistic) & 0.000000 \\
\hline
\end{tabular}

Table 7: Joint unrestricted estimation of equations (6) to (8)

Dependent Variable: R

Method: ML - ARCH

Date: 04/13/06 Time: 17:33

Sample(adjusted): 31492

Included observations: 1490 after adjusting endpoints

Convergence achieved after 13 iterations

\begin{tabular}{l|l|l|l|l}
\hline & Coefficient & Std. Error & Z-Statistic & Prob. \\
\hline $\mathrm{C}$ & -0.000122 & 0.000476 & -0.256652 & 0.7974 \\
$\mathrm{R}(-1)$ & -0.475189 & 0.024236 & -19.60644 & 0.0000 \\
\hline \multicolumn{5}{c}{ Variance Equation } \\
\hline $\mathrm{C}$ & $4.58 \mathrm{E}-06$ & $4.28 \mathrm{E}-05$ & 0.107059 & 0.9147 \\
ARCH(1) & 0.164251 & 0.030971 & 5.303439 & 0.0000 \\
GARCH(1) & 0.702765 & 0.052549 & 13.37358 & 0.0000 \\
V & $6.01 \mathrm{E}-07$ & $3.69 \mathrm{E}-07$ & 1.628243 & 0.1035 \\
\hline R-squared & 0.219414 & Mean dependent var & $4.82 \mathrm{E}-05$ \\
Adjusted R-squared & 0.216784 & S.D. dependent var & 0.026101 \\
S.E. of regression & 0.023099 & Akaike info criterion & -4.751202 \\
Sum squared resid & 0.791842 & Schwarz criterion & -4.729833 \\
Log likelihood & 3545.646 & F-statistic & 83.42729 \\
Durbin-Watson stat & 2.283296 & Prob(F-statistic) & 0.000000 \\
\hline
\end{tabular}

We first estimate the parameters of equation (8) under the assumption that $\gamma_{1}$ is equal to 0 (restricted variance equation), which is shown on Table 6. From this we found parameters 
$\alpha_{1}$ and $\beta_{1}$ to be positive and significant. The observed sum $\left(\alpha_{1}+\beta_{1}\right)$ is 0.93 , indicating high persistence (hysteresis) in conditional volatility.

In the next step we were interested in the unrestricted conditional variance equation (Table 7). We found the estimated parameter $\gamma_{1}$ to be positive although significant only at the $10 \%$ level. Most interestingly, our data show a decrease in the persistence of volatility when including trading volume in equation (8), since the sum $\left(\alpha_{1}+\beta_{1}\right)$ falls to 0.86 in the unrestricted regression.

As pointed out by Piscitelli et al. (1999), the term hysteresis, which comes from physics, has been used in economic and econometric theory to refer to two distinct phenomena: persistence in deviations from equilibria, possibly followed by an eventual return to a previous equilibrium state; and the presence of unit roots in systems of linear difference or differential equations, implying that a single temporary shock permanently changes the equilibrium path of the system. In empirical economics, however, hysteresis is used more loosely to mean that temporary shocks are observed to result in a persistent change from a previously persistent system state, even though this previously persistent system state cannot be verified to be in equilibrium and the persistent change cannot be verified to be permanent.

To some extent our results for the Brazilian stock market show weak support for the MDH model. Trading volume as a proxy for the flow of information has at least a weak effect on stock returns volatility. On the other hand, we found the parameters $\alpha_{1}$ and $\beta_{1}$ to remain significant after including trading volume in equation (8). This can be seen as a signal that either trading volume might only be a rough proxy for the flow of information, or that the assumption of the MDH that information flows simultaneously into the market might be incorrect.

\subsection{Causal Relationships}

In order to test for causality we estimate a bivariate VAR(1) model, the results of which are shown on Table 8. The VAR's order was chosen based on the minimization of the Akaike and the Schwartz information criteria. From Table 8, we can see that the influence of lagged trading volume on stock returns is weak with the corresponding parameter being significant only at the $12 \%$ level (t-statistic $=-1.1832$ ). Besides, it is clear that the influence of lagged stock returns on trading volume is insignificant. However, a better picture concerning the influences of trading volume on stock returns and vice-versa can be obtained from Granger-causality tests. Table 9 reports our results of Granger testing for unidirectional causality between returns and trading volume, and between squared returns (volatility) and trading volume, respectively, based on the VAR(1) results shown on Table 8 .

As expected, we cannot find evidence of a causal relationship between stock returns and trading volume in either direction. That means that short-run forecasts of current or future stock returns in most cases cannot be improved by knowledge of recent trading volume data and vice versa. In addition, Table 9 illustrates that return volatility Granger-causes trading volume and that trading volume Granger-causes return volatility even more strongly. This means that causality between trading volume and stock return volatility occurs in both directions, although more intensely from volume to volatility. This result confirms previous findings that stock price changes in any direction have information content for forthcoming trading activities (MESTEL, GURGUL; MAJSDOZ, 2003).

The bi-causal relationship between trading volume and stock return volatility can be seen as evidence that new information arrival follow a simultaneous process. This implies that 
the strong form of market efficiency holds since private information is reflected on stock prices.

\section{CONCLUSION}

In this study the empirical relationship between stock returns, return volatility and trading volume was examined by using data from the Brazilian stock market. We found evidence of a significant contemporaneous relationship between return volatility and trading volume, which is detected in the cross-correlation analysis. However, a simultaneous equation analysis show that stock returns depend on trading volume, but that this does not apply the other way round.

Table 8: VAR(1) results

\begin{tabular}{l|c|c}
\hline \multicolumn{3}{c}{$\begin{array}{c}\text { Included observations: } 1490 \text { after adjusting endpoints } \\
\text { Standard errors \& }\end{array}$} \\
\hline & $\mathrm{R}$ t-statistics in parentheses & $\mathrm{V}$ \\
$\mathrm{R}(-1)$ & -0.464387 & 19.87980 \\
& $(0.02300)$ & $(41.0352)$ \\
& $(-20.1874)$ & $(0.48446)$ \\
V(-1) & $-1.68 \mathrm{E}-05$ & -0.254830 \\
& $(1.4 \mathrm{E}-05)$ & $(0.02525)$ \\
& $(-1.18372)$ & $(-10.0916)$ \\
C R-squared & & \\
& 0.001830 & 133.2501 \\
& $(0.00162)$ & $(2.88583)$ \\
& $(1.13095)$ & $(46.1740)$ \\
\hline Adj. R-squared & 0.220252 & 0.064372 \\
Sum sq. resids & 0.219203 & 0.063114 \\
S.E. equation & 0.790993 & 2517002. \\
Log likelihood & 0.023064 & 41.14209 \\
Akaike AIC & 3503.825 & -7651.094 \\
Schwarz SC & 3503.829 & -7651.090 \\
Mean dependent & 3503.840 & -7651.079 \\
S.D. dependent & $4.82 \mathrm{E}-05$ & 106.1866 \\
\hline Determinant Residual Covariance & 0.026101 & 42.50528 \\
Log Likelihood & & 0.884177 \\
Akaike Information Criteria & & -4136.729 \\
Schwarz Criteria & & -4136.721 \\
\hline
\end{tabular}


Table 9: Pairwise Granger Causality Tests

\begin{tabular}{|c|c|c|c|}
\hline $\begin{array}{l}\text { Sample: } 11492 \\
\text { Lags: } 1\end{array}$ & & & \\
\hline Null Hypothesis: & Obs & F-Statistic & Probability \\
\hline $\mathrm{R}$ does not Granger Cause V & 1490 & 0.23470 & 0.62813 \\
\hline V does not Granger Cause $\mathrm{R}$ & & 1.40119 & 0.23671 \\
\hline $\mathrm{R}^{2}$ does not Granger Cause V & 1490 & 5.28956 & 0.02159 \\
\hline$V$ does not Granger Cause $\mathrm{R}^{2}$ & & 12.2245 & 0.00049 \\
\hline
\end{tabular}

We also find that higher trading volume is associated with an increase in return volatility and that this relationship is asymmetrical, since it is more pronounced when stock prices increase than vice versa.

Our GARCH(1,1) estimation of stock returns and volatility confirm the ARCH effects and high hysteresis in conditional volatility. The hysteresis of variance over time partly declines if one includes trading volume as a proxy for information arrivals in the equation of conditional volatility. The GARCH estimation provide an almost negligible support for the MDH (Mixed of Distribution Hypothesis), since the inclusion of trading volume in the variance equation (unrestricted estimation) produces a rather weakly significant coefficient and it does not relieve the strong ARCH effects observed in the restricted variance equation.

When it comes to Granger-causality, our results present no signs of causality between trading volume and stock returns. However, Granger causality between trading volume and return volatility is remarkably evident in both directions, although stronger from trading volume to return volatility, which indicates that information might flow simultaneously rather than sequentially into the market.

Our findings differ in some aspects from those obtained in a similar study (MESTEL, GURGUL; MAJDOSZ, 2003). While they find only weak support for a contemporaneous as well as a dynamic relationship between stock returns and trading volume, we find significant contemporaneous and dynamic relationships between these variables. One of the reasons that can explain these differences is the method used to estimate the simultaneous equations system, consisting of Equations (3) and (4), since those authors apply 2SLS, whereas we employ full-information maximum likelihood, which tends to be more robust. Another difference relates to the Granger-causality tests. While those authors find weak evidence of a causal relationship between stock returns and trading volume, we find no causality at all between these two variables. Besides, while they find that return volatility precedes trading volume, we come across some hard evidence of a mutual causality between these two variables. Of course, since the statistical and econometric methods used in both studies are similar, the differences noticed with respect to the empirical results are likely to be a consequence of different microstructure and institutional factors, which differentiate a small but developed stock market (Austria) from a relatively small but emerging stock market (Brazil).

We believe our results can help to better understand the microstructure of stock markets, especially of the emerging variety. However, since the Brazilian stock market is thin when compared to more developed markets, additional comparable investigations with respect to other markets are desirable. 


\section{REFERENCES}

ANDERSEN, T.G. (1996) Return volatility and trading volume: An information flow interpretation of stochastic volatility. Journal of Finance 51 (1): 169-204.

BRAILSFORD, T.J. (1996) The empirical relationship between trading volume, returns and volatility. Accounting and Finance 35 (1): 89-111.

BROCK, W.A.; LEBARON, B.D. (1996) A dynamic structural model for stock return volatility and trading volume. The Review of Economics and Statistics 78 (1): 94-110.

CLARK, P.K. (1973) A subordinated stochastic process model with finite variance for speculative prices. Econometrica 41 (1): 135-155.

DARRAT, A.F., RAHMAN, S.; ZHONG, M. (2003) Intraday trading volume and return volatility of the DJIA stocks: A note. Journal of Banking and Finance 27 (10): 2035-2043.

EPPS, T.W; EPPS, M.L. (1976) The stochastic dependence of security price changes and transaction volumes: Implications for the mixture-of-distribution hypothesis. Econometrica 44 (2): 305-321.

GALLO, G.M.; PACINI, B. (2000) The effects of trading activity on market volatility. The European Journal of Finance 6 (2): 163-175.

GRANGER, C. (1969). Investigating causal relations by economic models and cross-spectral methods. Econometrica 37 (3): 424-438.

HIEMSTRA, C.; JONES, J.D. (1994) Testing for linear and nonlinear Granger causality in the stock price - volume relation. Journal of Finance 49 (5): 1639-1664.

IPEA - Instituto de Pesquisa Econômica Aplicada (2006). Database accessed in 2006. www.ipeadata.gov.br.

KARPOFF, J.M. (1987) The relation between price changes and trading volume: A survey. Journal of Financial and Quantitative Analysis 22 (1): 109-126.

LAMOUREUX, C.G.; LASTRAPES, W.D. (1990) Heteroscedasticity in stock return data: Volume versus GARCH effects. Journal of Finance 45 (1): 221-229.

LAMOUREUX, C.G.; LASTRAPES, W.D. (1994) Endogenous trading volume and momentum in stock-return volatility. Journal of Business and Economic Statistics 12 (2): 253-260.

LEE, B-S; RUI, O.M. (2002) The dynamic relationship between stock returns and trading volume: Domestic and cross-country evidence. Journal of Banking and Finance 26 (1): 5178 .

MACKINNON, J.G. (1991) Critical Values for Cointegration Tests, Chapter 13 in Long-run Economic Relationships: Readings in Cointegration, edited by R.F.Engle and C.W.J. Granger, Oxford University Press. 
MESTEL, R.; GURGUL, H.; MAJDOSZ, P. (2003) The Empirical Relationship between stock returns, return volatility and trading volume on the Austrian stock market. University of Graz, Institute of Banking and Finance, Research Paper.

OMRAN, M.F.; MCKENZIE, E. (2000) Heteroscedasticity in stock returns data revisited: Volume versus GARCH effects. Applied Financial Economics 10 (5): 553-560.

PISCITELLI, L.; CROSS, R.; GRINFELD; M.; LAMBA, H. (2000) A test for strong hysteresis, Computational Economics, Volume 15, Numbers 1-2, April 2000: 59 - 78.

RITTER, J.R. (2003) Behavioral Finance. Pacific-Basin Finance Journal 11(4): 429-437.

TAUCHEN, G.; PITTS, M. (1983) The price variability-volume relationship on speculative markets. Econometrica 51 (2): 485-505. 